\title{
INFLUENCE OF PALM METHYL ESTER (PME) AS AN ALTERNATIVE FUEL IN MULTICYLINDER DIESEL ENGINE
}

\author{
Mohd Hafizil M. Yasin ${ }^{1}$, R. Mamat ${ }^{1}$, K.V. Sharma ${ }^{2}$ and Ahmad Fitri Yusop ${ }^{1}$ \\ ${ }^{1}$ Faculty of Mechanical Engineering, Universiti Malaysia Pahang \\ 26600 Pekan, Malaysia \\ Telephone: +609-8400964; Fax: +609-424 2202 \\ E-mail: hafizil@psmza.edu.my, mhafizil80@yahoo.com \\ ${ }^{2}$ Jawaharlal Nehru Technological University Hyderabad, \\ Kukatpally, Hyderabad 500 085, Andhra Pradesh, India
}

\begin{abstract}
Palm oil is one of the vegetable oil, which is converted to biodiesel through a transesterification process using methanol as the catalyst. Palm oil biodiesel or palm methyl ester (PME) can be used in diesel engines without any modification, and can be blended with conventional diesel to produce different proportions of PME-diesel blend fuels. The physical properties of PME were evaluated experimentally and theoretically. The effect of using neat PME as fuel on engine performance and emissions was evaluated using a commercial four-cylinder four-stroke IDI diesel engine. The experimental results on an engine operated with PME exhibited higher brake specific fuel consumption in comparison with the conventional fuel. With respect to the incylinder pressure and heat release rate, these increased features by over $8.11 \%$ and $9.3 \%$ with PME compared to conventional diesel. The overall results show that PME surpassed the diesel combustion quality due to its psychochemical properties and higher oxygen content.
\end{abstract}

Keywords: Palm methyl ester (PME); engine performance; combustion characteristics; diesel engine.

\section{INTRODUCTION}

Palm oil is considered a 'golden crop', and is the most productive oil crop that continues to significantly contribute to the increase in the global oil and fat trade. With the new trend in the search for alternative fuels that can replace conventional diesel, among the vegetable oils palm oil is considered to be the most reliable and highly value-added for conversion into biodiesel. Palm oil is an export-oriented commodity for Malaysia, because the population only consumed $28 \%$ of the country's total palm oil production (Abdullah, 2011; Azad, Ameer Uddin, \& Alam, 2012; Rahim, Mamat, Taib, \& Abdullah, 2012). Most of the palm oil is converted into oil and fat (around 78\%), and $15 \%$ is for biodiesel production in Malaysia. Of the global palm oil production, an average of $26.6 \%$ is for oil and fat production. In 2011, Indonesia provided almost $44.5 \%$ of the total world production, followed by Malaysia with $41.3 \%$ and other countries such as Thailand Nigeria and Colombia (MPOB, 2012). Major palm oil importers are from China, India, the EU-27 and Pakistan.

As one of major palm oil producers and exporters in the world, Malaysia has set a target to cater for the world market demand for biodiesel fuel production, due to the high yield oil stocks per hectare and insufficient stocks from other vegetable oils such as 
soybean, rapeseed and sunflower oil. In August 2005, the National Biofuel Policy was launched to promote the use of sustainable energy sources including biodiesel and biomass, with support in terms of subsidized prices for the industry. This was followed by the National Energy Policy in 2006, which has driven Malaysia towards assisting the future energy sector development in securing energy sources and minimizing the effect of pollution on the environment. Palm oil is converted into biodiesel or palm methyl ester (PME) by the transesterification process, using methanol as the catalyst. In the preparation process, one mole of methanol is required for three moles of palm oil in the transesterification process, where the PME chemical formula is expressed as in Eq. (1):

$$
\mathrm{R}-\mathrm{COO}-\mathrm{CH}_{3}
$$

Unlike conventional diesel, PME has a higher oxygen and lower sulfur content, but no aromatic ring in the molecule. These unique properties confirm that PME is more biodegradable and environmentally-safe compared to conventional diesel. Viscosity can be defined as a measure of resistance for a fluid to flow, from this definition a fluid with higher viscosity has a high motion resistance. Biodiesel viscosity is an crucial parameter, which influences fuel injection timing and ignition delay in combustion systems (Ayhan, 2011; Sundar Raj \& Sendilvelan, 2010), thus it is investigated in this work. According to Masjuki, Abdulmuin \& Sii (1996), de Almeida, Belchior, Nascimento, Vieira \& Fleury (2002), and Gerhard (2010), the higher viscosity of biodiesel leads to poor atomization and the clogging of fuel lines, as well as carbon deposits, and thus causes higher injection volumes and pressures when operating at lower engine operating temperatures. The higher viscosity of biodiesel is mostly due to the higher length of the fatty acid chains of ethyl esters. This research work aims to study the effect of PME on the performance and combustion characteristics of a fourcylinder four-stroke diesel engine, with speeds ranging from $1000 \mathrm{rpm}$ to $3500 \mathrm{rpm}$.

\section{EXPERIMENTAL SET UP}

A commercial Mitsubishi 4D68 SOHC in-line four-cylinder four-stroke, indirect injection diesel engine equipped with diaphragm type EGR was used in this study. The engine is water-cooled with a maximum power of $65 \mathrm{~kW}$ at $4500 \mathrm{rpm}$; the detailed specification of this engine is presented in Table 2. The engine was coupled to a $150 \mathrm{~kW}$ ECB eddy current dynamometer equipped with a Dynalec controller, which is used to control the engine speeds and torques. The dynamometer was carefully and regularly calibrated to ensure accurate data could be obtained.

Table 1. Specification of a Mitsubishi 4D68 diesel engine

\begin{tabular}{lll}
\hline Number of cylinders & 4 in-line \\
\hline Combustion chamber & Swirl chamber & \\
Total displacement $(\mathrm{cm})$ & $1.998 \mathrm{cc}$ \\
Cylinder bore $(\mathrm{mm}) \times$ Piston stroke $(\mathrm{mm})$ & $82.7 \times 93$ \\
Bore/stroke ratio & 0.89 & \\
& Opens (BTDC) $20^{\circ}$ \\
Valve timing $\quad$ Intake valve & Closes (ATDC) $48^{\circ}$ \\
& & Opens (BBDC) $54^{\circ}$ \\
& Exhaust valve & Closes (ATDC) $22^{\circ}$ \\
\hline
\end{tabular}


A GEMU rotameter was used to measure the flow rate of the cooling water within the engine cooling system. Two separate fuel tanks equipped with thermocouples and fuel valve systems were used to deliver the conventional fuel and PME. In the fuel delivery system, fuel flow meter brand AIC 1204 was used to separately measure the fuel consumption rate of both fuels. As for the fuel line pressure measurement, Cole Palmer digital pressure gauges were mounted along the fuel line of the engine and the fuel return line. Figure 1 shows the engine set up.

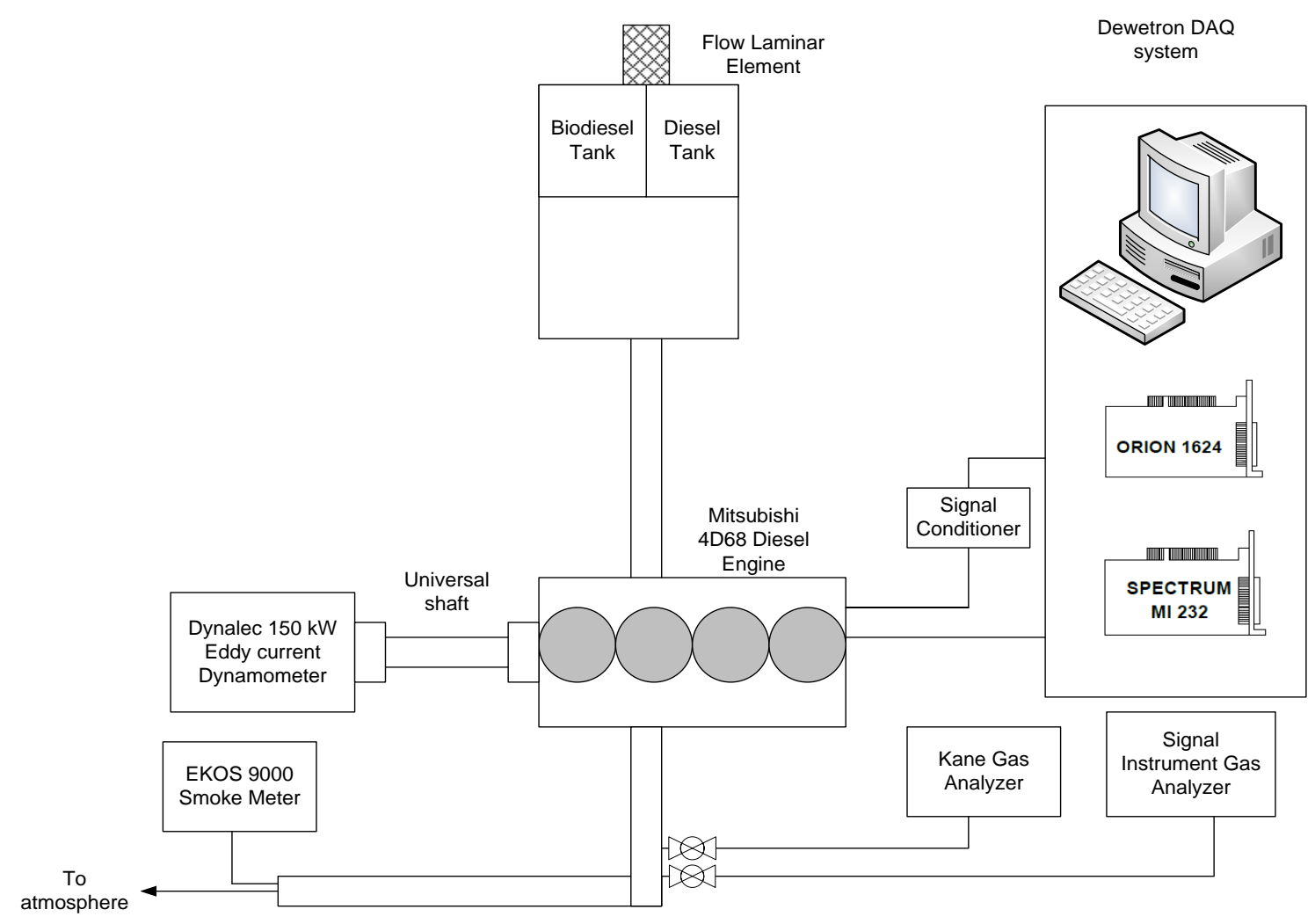

Figure 1. Engine test bed apparatus

Flow laminar elements (FLE) equipped with a Wycombe manometer and a Centertek air velocity manometer were used to measure the air pressure and airflow rate at the air inlet charge. Relative humidity and ambient temperature were measured using a EL-USB-RT device, so that accurate air density data could be used in the calculations. A Kistler Thermo-Comp water-cooled pressure transducer was mounted at the engine cylinder head to measure the in-cylinder pressure and carefully monitor knocking phenomenon. A DEWETRON data acquisition (DAQ) system was employed to gather and analyze the signals from the charge amplifier and crank angle encoder. A KANE gas analyzer was used to measure the corresponding levels of $\mathrm{NO} x, \mathrm{CO}, \mathrm{CO}_{2}$ and $\mathrm{O}_{2}$. The device is regularly calibrated to maintain its accuracy. A EKOS 9000 Smoke Tester was used to measure smoke density in the exhaust piping. The exhaust gas analyzers are calibrated before making the measurements. K-type thermocouples were used to measure different temperatures within the engine, such as exhaust, coolant and inlet air temperatures. 
Table 2. KANE gas analyzer specifications.

\begin{tabular}{lcc}
\hline \multicolumn{1}{c}{ Gas Measurement } & Accuracy & Range \\
\hline Oxygen & $\pm 0.2 \%$ & $0-21 \%$ \\
Carbon monoxide $(\mathrm{CO})$ & $\pm 20 \mathrm{ppm}<400 \mathrm{ppm}$ & $0-10,000 \mathrm{ppm}$ \\
Nitric oxide & $\pm 5 \mathrm{ppm} 100 \mathrm{ppm}$ & $0-5000 \mathrm{ppm}$ \\
Nitrogen dioxide & $\pm 5 \mathrm{ppm}<100 \mathrm{ppm}$ & $0-1000 \mathrm{ppm}$ \\
Sulphur dioxide & $\pm 5 \mathrm{ppm}<100 \mathrm{ppm}$ & $0-5000 \mathrm{ppm}$ \\
\hline
\end{tabular}

The engine was fuelled with conventional diesel during the initial operation and warm-up, followed by PME. Each fuel test was repeated three times to provide conclusive results, and a repeatability of the results of more than $95 \%$ was achieved. Correction factors according to SAE J1349 for the atmospheric condition and brake power have been employed. The properties of the fuel are tested using the standard ASTM method. The fuel properties of the conventional diesel and PME used in this study are presented in Table 1 .

Table 3. Fuel properties for conventional diesel and PME.

\begin{tabular}{lcc}
\hline \multicolumn{1}{c}{ Property } & Diesel & PME \\
\hline Heat value $\left(\mathrm{MJ} \mathrm{kg}^{-1}\right)$ & 45.28 & 41.3 \\
Cloud point $\left({ }^{\circ} \mathrm{C}\right)$ & 18 & 14 \\
Density @ $15^{\circ} \mathrm{C}\left(\mathrm{kg} / \mathrm{m}^{3}\right)$ & 853.8 & 867 \\
Flash point $\left({ }^{\circ} \mathrm{C}\right)$ & 93 & 165 \\
Pour point $\left({ }^{\circ} \mathrm{C}\right)$ & 12 & 15 \\
Cetane number & 54.6 & 67 \\
Kinematic viscosity at $40 \mathrm{C}\left(\mathrm{mm}^{2} / \mathrm{s}\right)$ & 2.6 & 4.53 \\
Sulfur content $(\mathrm{mg} / \mathrm{kg})$ & 12 & 6 \\
Carbon residue content $(\mathrm{wt} . \%)$ & $<0.01$ & $<0.01$ \\
\hline
\end{tabular}

\section{RESULTS AND DISCUSSION}

\section{Specific Fuel Consumption}

The brake specific fuel consumption (BSFC) can be defined as the mass fuel flow rate in $\mathrm{g} / \mathrm{hr}$ at one engine brake power output in $\mathrm{kW}$. This parameter is important in order to analyze the engine's performance and the efficiency of the fuel supplied to the engine. Figure 2 presents the brake specific fuel consumption (BSFC) against diesel engine speeds using conventional diesel and PME. The results from Figure 2 demonstrated that conventional diesel has a lower BSFC in comparison with PME. The increases in BSFC can be attributed to the low energy content of PME, which is approximately $2.1 \%$ less than conventional diesel. The higher the content of palm oil in the biodiesel, the lower its heating value. The increase in BSFC when operating with biodiesel shows that the diesel engine has consumed more fuel to gain a similar power output, as compared to conventional diesel PME has a higher energy content. 


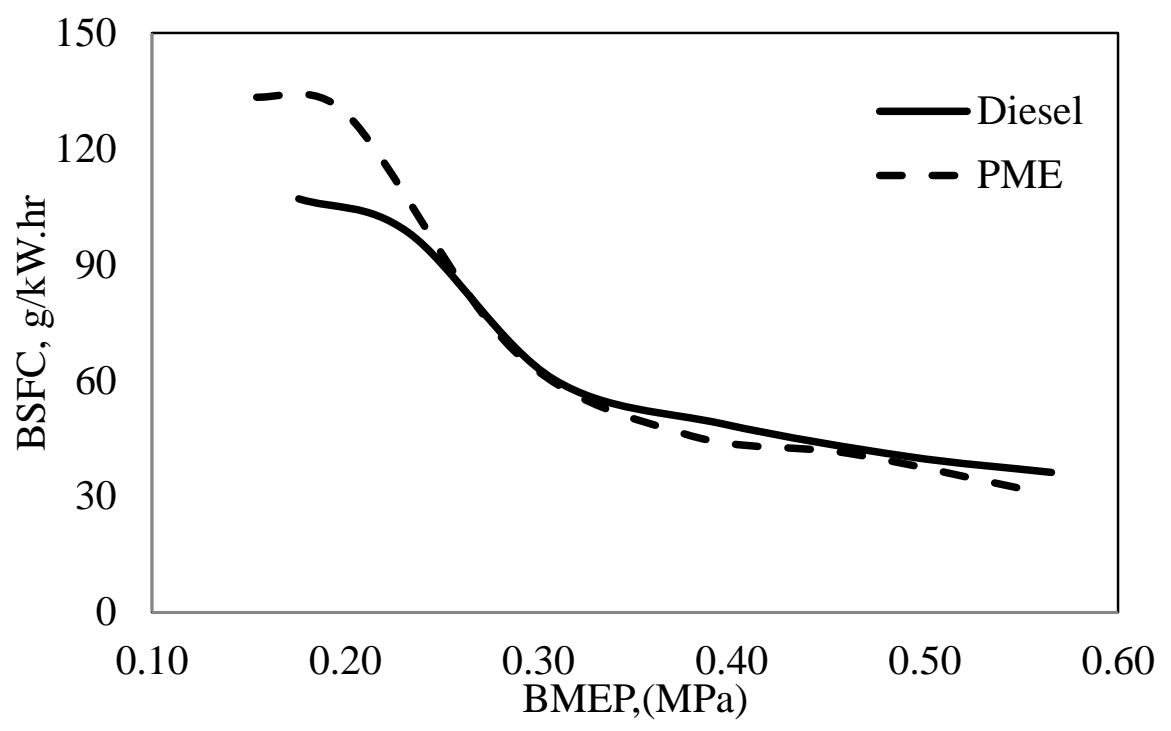

Figure 2. BSFC for conventional diesel and PME fuel (n=3500 rpm)

\section{Combustion Characteristics and Rate of Heat Release}

In this study, the engine tests with conventional diesel and PME were conducted at the same operating engine speeds of $3500 \mathrm{rpm}$. This research work covers the combustion characteristics and heat release rate based on data for the measured in-cylinder pressure and crank angle degree $\left({ }^{\circ} \mathrm{CA}\right)$ at the same brake mean effective pressure (BMEP). The values of in-cylinder pressures of the diesel engine and corresponding crank angle degree, when operated with PME and conventional diesel under the same operating conditions, are presented in Figure 3. It is observed that that peak pressure developed for the tested fuels, conventional diesel and PME, is away from the TDC. The maximum peak cylinder pressure for PME was observed as 61.6 bar at $14{ }^{\circ} \mathrm{CA}$, while the conventional diesel's peak cylinder pressure reached 56.6 bar. The increase in cylinder pressure means an increase in cylinder temperature. This result proved that PME that has a higher oxygen content, similar to other biodiesel fuels, compared to conventional diesel, resulting in the complete burning of the air-mixed fuel in the cylinder and an increase in the heat release rate. In order to obtain a thorough understanding of the effects of biodiesel, especially PME, on combustion characteristics, the basic combustion parameters are determined based on heat release analysis, and the results are shown in Figure 4. The heat release rate from the engine, $\frac{d x}{d \varphi}$, is computed with the following equation:

$$
\begin{gathered}
\frac{d x}{d \varphi}=p \frac{C_{p}}{R} \frac{d V}{d \varphi}+V \frac{C_{v}}{R} \frac{d p}{d \varphi}+m T \frac{d C_{v}}{d \varphi}+\frac{d Q_{w}}{d \varphi} \\
\frac{d Q_{w}}{d \varphi}=h_{c} A\left(T-T_{w}\right)
\end{gathered}
$$

where: $p$ is the cylinder gas pressure, $C_{p}$ is the specific heat capacity at constant pressure, $C_{v}$ is the constant volume specific heat, $R$ is the gas constant, $h_{c}$ is the heat transfer coefficient, $A$ the wall area, and $T_{w}$ the wall temperature. 


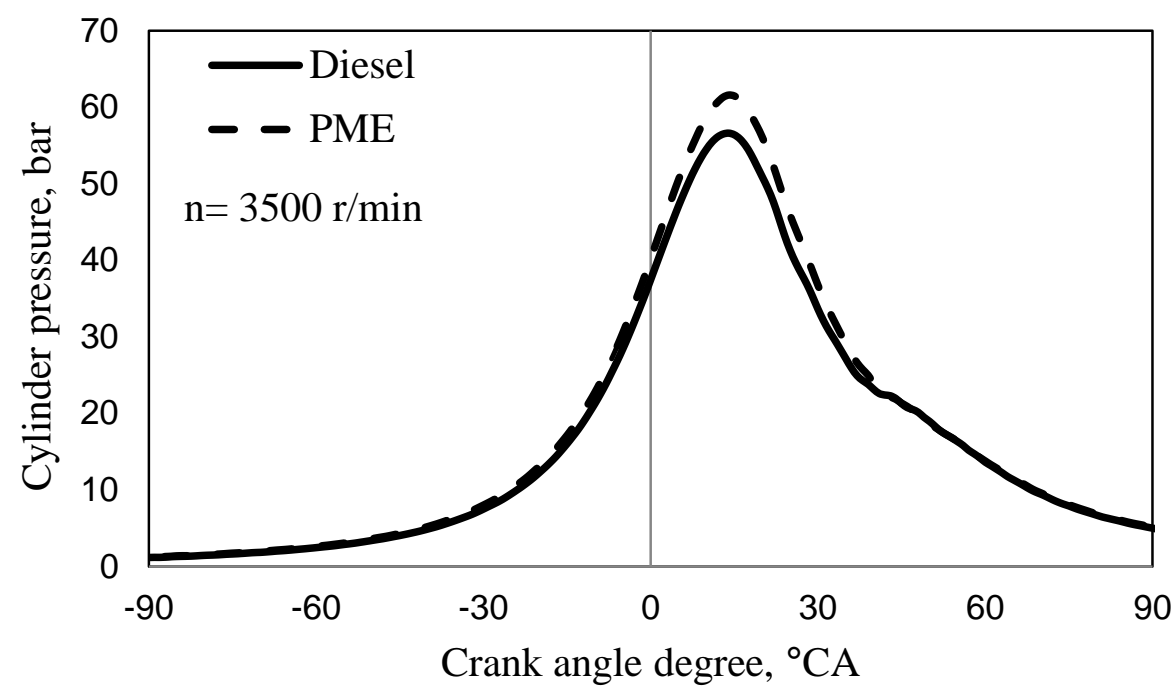

Figure 3. Peak in-cylinder pressure for conventional diesel and PME.

Figure 4 illustrates the maximum rate of heat release corresponding to crank angle for PME 100 and conventional diesel as the baseline fuel. Results show that the maximum rate of heat release for PME 100 is higher compared to conventional diesel. Since fuel vaporization starts during ignition delay, a negative heat release is observed at the beginning, before the start of combustion, and then the heat release rate becomes positive. The ignition time is the start of heat release during combustion. The time interval from the beginning of heat release to the end of the heat release can be referred to as the total combustion period. The graph show that conventional diesel and PME have similar heat release rate patterns before initial combustion, but at the peak PME surpasses the conventional diesel by almost $5 \%$ before suddenly dipping down.

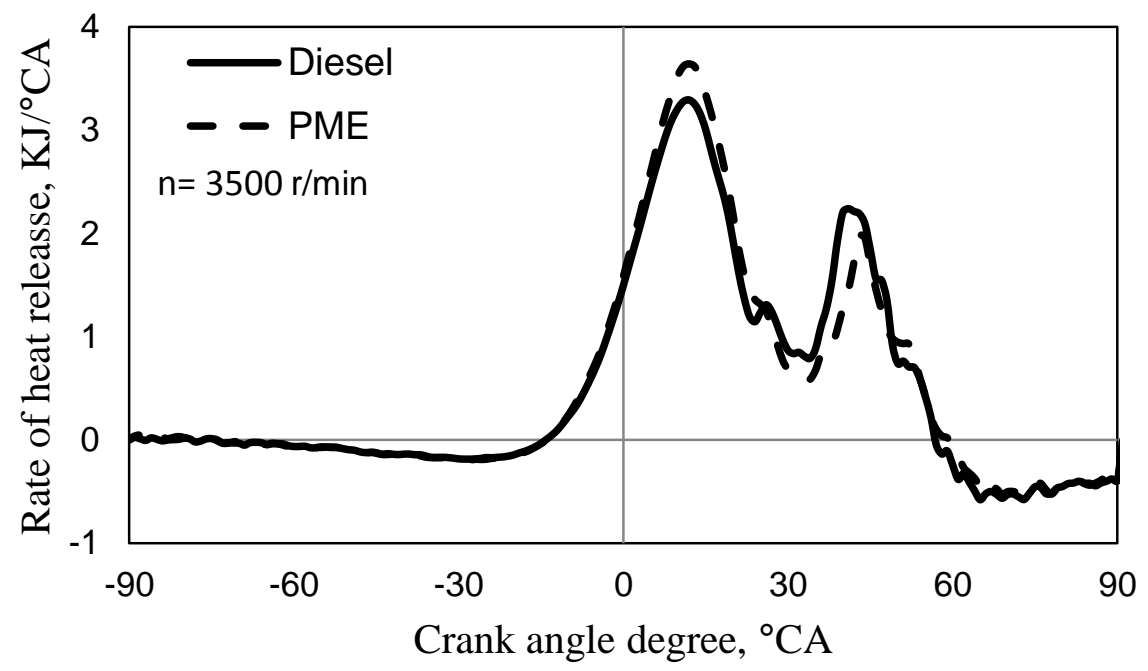

Figure 4. Peak rate of heat release for conventional diesel and PME.

Figure 5 presents the in-cylinder pressure against volume displacement for conventional diesel and PME fuels. It is observed that the peak cylinder pressure for 
PME is higher compared to that of conventional diesel, with a similar volume displacement. Among the main factors that contribute to the higher peak cylinder pressure for biodiesel is the presence of oxygen molecules which bring about more complete combustion (Mustafa, 2007), and also result in higher in-cylinder temperatures.

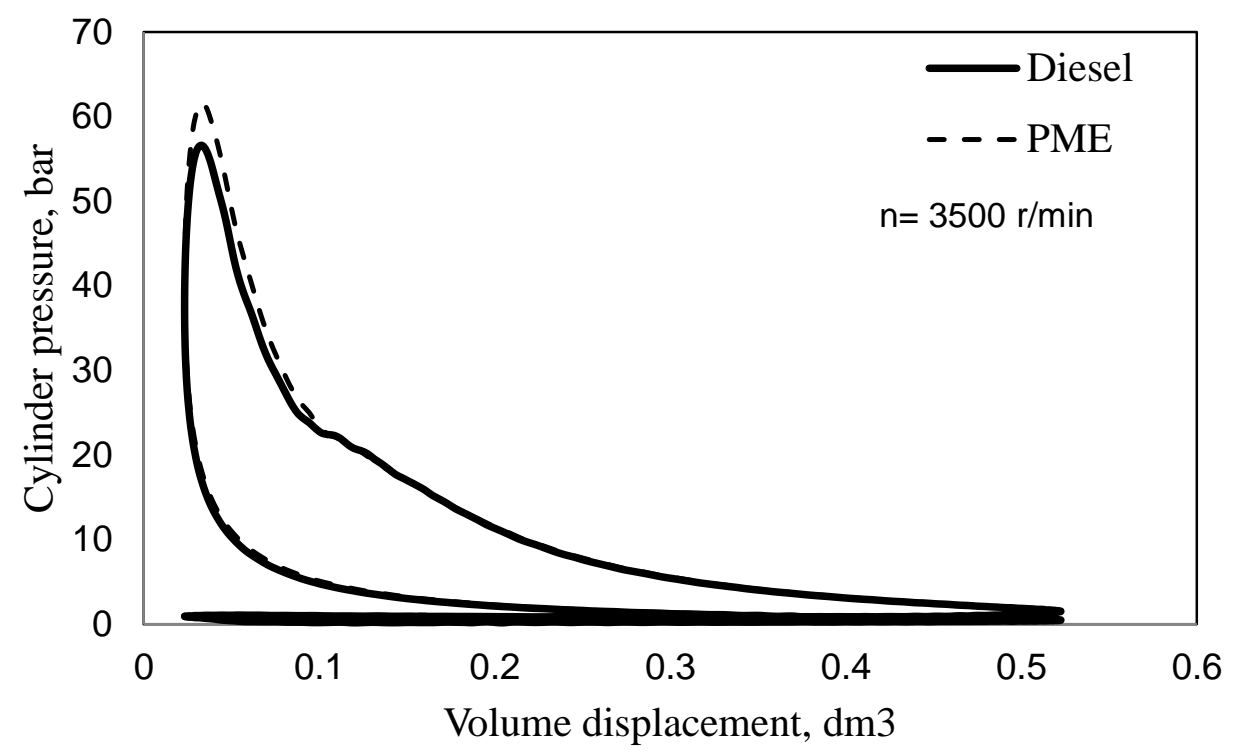

Figure 5. Peak in-cylinder pressure against volume displacement for conventional diesel and PME.

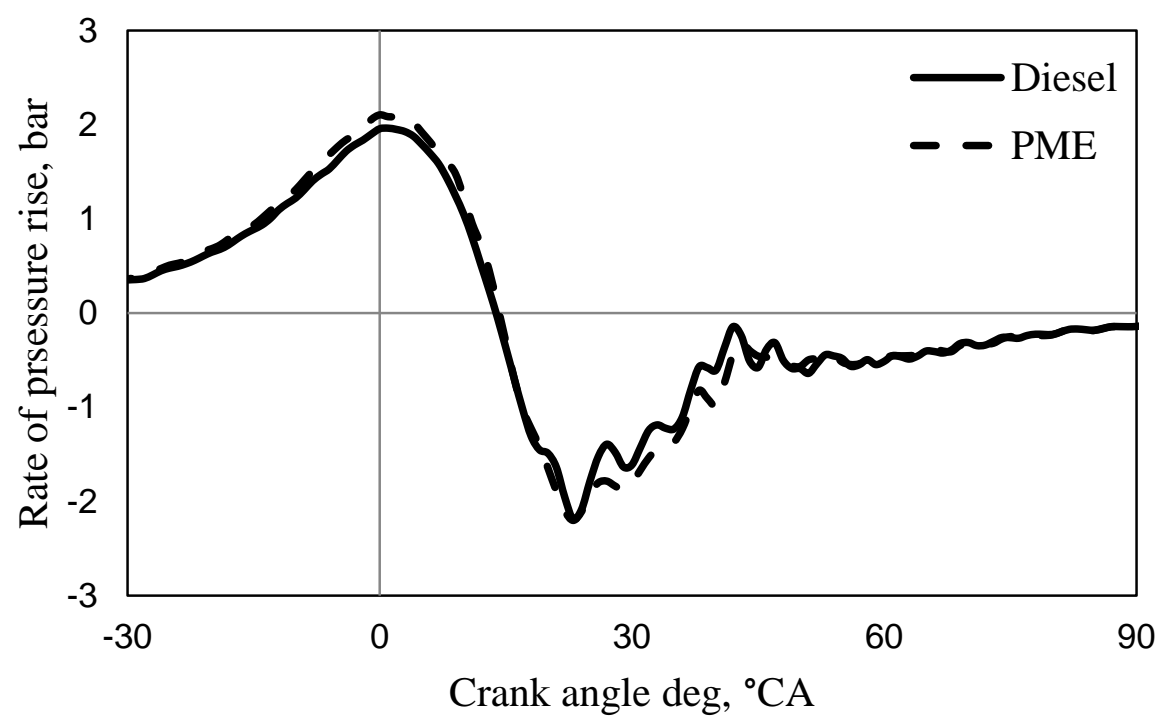

Figure 6. Peak rate of pressure rise for conventional diesel and PME.

The rate of pressure rise (RoPR) is defined as the rate of load imposed on the cylinder head and block during the combustion period (Murugan, Ramaswamy \& Nagarajan, 2008). The RoPR for conventional diesel and PME fuels is presented in Figure 6. It is observed that the RoPR of PME is $6.67 \%$ higher compared to conventional diesel, due to the higher Cetane number and oxygen concentration. A 
higher cetane number contributes to an advanced autoignition and shorter injection delay. The RoPR increases with an increasing engine load for the tested fuels due to the increasing quantity of fuel being injected into the cylinder per ${ }^{\circ} \mathrm{CA}$. The mass fraction burned for the fuel represents the percentage of fuel combusted within the cylinder within a certain combustion period. This parameter greatly depends on the combustion chamber conditions, including peak cylinder pressure as well as the ignition delay period. Figure 7 presents the mass fraction burn against crank angle degree for the conventional diesel and PME fuels. It can be observed that the mass fraction burned for PME achieved $69.9 \%$ at $26{ }^{\circ} \mathrm{CA}$, compared to conventional diesel with $63.5 \%$ at the same crank angle degree.

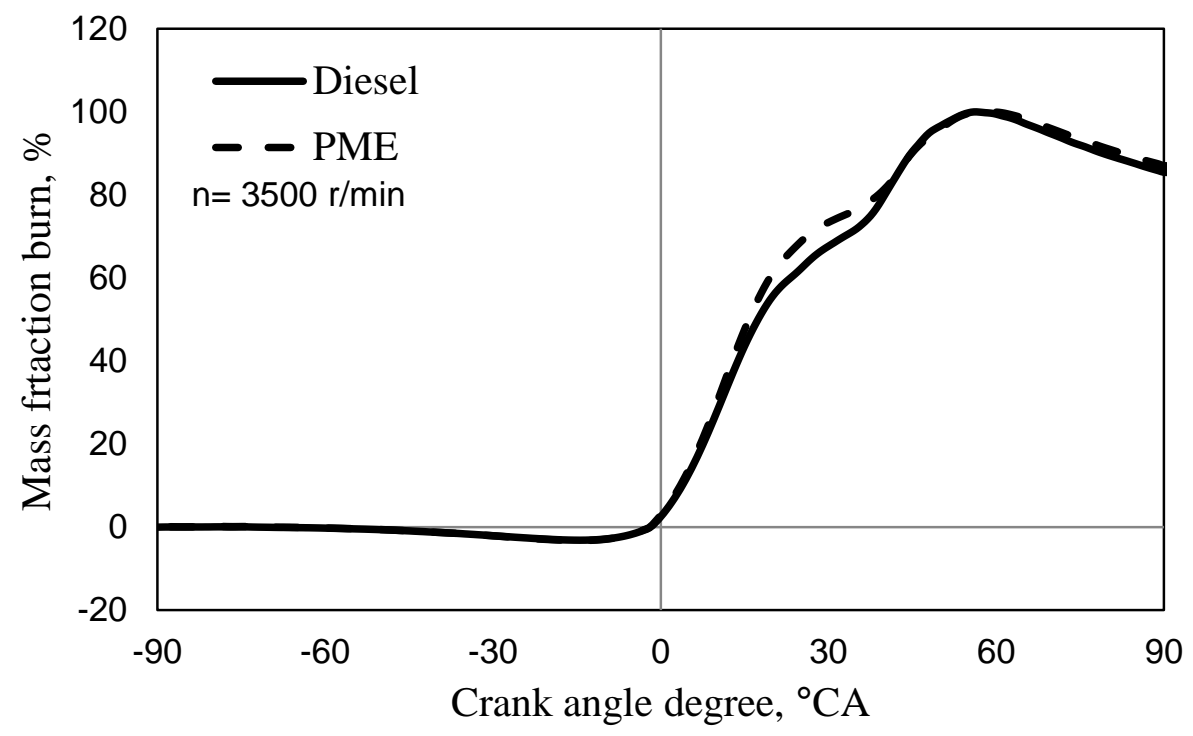

Figure 7. Mass fraction burn for conventional diesel and PME.

\section{CONCLUSION}

The influence of neat PME on the performance and combustion characteristics of a fourcylinder four-stroke IDI diesel engine have been investigated, and then compared to conventional diesel as the baseline fuel. The following main conclusions can be made:

1. The BSFC for PME is increased, but the BSFC for conventional diesel decreases with increasing engine speed from $1000 \mathrm{rpm}$ to $3500 \mathrm{rpm}$.

2. The engine running with PME produced a slightly higher in-cylinder pressure and peak heat release rate compared to conventional diesel at a specific engine speed of $3500 \mathrm{rpm}$.

\section{ACKNOWLEDGEMENT}

Universiti Malaysia Pahang is greatly acknowledged for technical and financial support under the UMP Short Grant (RDU100334). 


\section{REFERENCES}

Abdullah, R. (2011). Oil palm industry in Malaysia: an overview and related issues. Malaysian Palm Oil Board (MPOB).

Ayhan, D. (2011). Competitive liquid biofuels from biomass. Applied Energy, 88 (1), 17-28.

Azad, A. K., Ameer Uddin, S. M., \& Alam, M. M. (2012). A comprehensive study of DI diesel engine performance with vegetable oil: an alternative boi-fuel source of energy. International Journal of Automotive and Mechanical Engineering, 5, 576-586.

de Almeida, S. C. A., Belchior, C. R., Nascimento, M. V. G., Vieira, L. d. S. R., \& Fleury, G. (2002). Performance of a diesel generator fuelled with palm oil. Fuel, 81(16), 2097-2102.

Gerhard, K. (2010). Biodiesel and renewable diesel: a comparison. Progress in Energy and Combustion Science, 36 (3), 364-373.

Masjuki H., Abdulmuin, M. Z., \& Sii, H. S. (1996). Indirect injection diesel engine operation on palm oil methyl esters and its emulsions. Proceedings of Institute of Mechanical Engineers, 211, 291-299.

MPOB (2012). Overview of the Malaysian oil palm industry 2011. Bangi, Selangor, Malaysian Palm Oil Board.

Murugan, S., Ramaswamy, M., \& Nagarajan, G. (2008). A comparative study on the performance, emission and combustion studies of a DI diesel engine using distilled tyre pyrolysis oil-diesel blends. Fuel, 87 (10), 2111-2121.

Mustafa, C. (2007). Combustion characteristics of a turbocharged DI compression ignition engine fueled with petroleum diesel fuels and biodiesel. Bioresource Technology, 98, 1167-1175.

Rahim, R. Mamat, R., Taib, M. Y., \& Abdullah, A. A. (2012). Influence of fuel temperature on a diesel engine performance operating with biodiesel blended. Journal of Mechanical Engineering and Sciences, 2, 226-236.

Sundar Raj, C., \& Sendilvelan, S. (2010). Effect of oxygenated hydrocarbon additives on exhaust emission of a diesel engine. International Journal of Automotive and Mechanical Engineering, 2, 144-156. 